\title{
The Impact of Alzheimer's Disease on the Life of Family Caregivers: A Phenomenological View
}

\author{
Berta Sheila Souza Ribeiro1, Luciana Krauss Rezende ${ }^{2 *}$, Selma Petra Chaves Sa ${ }^{3}$, \\ Wiliam César Alves Machado4 \\ ${ }^{1}$ Science of Health Care, Aurora Afonso Costa Nursing School, Fluminense Federal University, Human Resources \\ Management at the Anhanguera University Centre, Niterói, Brazil \\ ${ }^{2}$ Science of Health Care Graduate Program of the Aurora Afonso Costa Nursing School, Fluminense Federal \\ University, Developmental Disorders at the Mackenzie Presbyterian University, Niterói, Brazil \\ ${ }^{3}$ Nursing, Federal University of Rio de Janeiro, Department of Nursing Administration Fundamentals and of the \\ Fluminense Federal University and the Science of Health Care Graduate Program (MACCS) and Nursing \\ Graduate School (MPEA), Health Care for the Elderly in the UFF Nursing School, Niterói, Brazil \\ ${ }^{4}$ Graduate Program in Health and Hospital Space Technology, PPGSTEH and Graduate Program, \\ Federal University of the State of Rio de Janeiro, Rio de Janeiro, Brazil \\ Email: *lukrare@uol.com.br, niceshindo@gmail.com, rita.j.gray@gmail.com
}

Received 2 March 2016; accepted 25 April 2016; published 28 April 2016

Copyright (C) 2016 by authors and Scientific Research Publishing Inc.

This work is licensed under the Creative Commons Attribution International License (CC BY). http://creativecommons.org/licenses/by/4.0/

(c) $\underset{\mathrm{EY}}{\mathrm{B}}$ Open Access

\begin{abstract}
The objectives of this study are to describe the perception of caregivers about the process of caring for elders with Alzheimer's disease, analyze the impact of the care process on the caregiver's life from the biological and emotional aspects, and discuss the changes in the caregiver's life in the light of Gestalt Therapy. This was a qualitative and descriptive study with a phenomenological analysis. The results showed that family caregivers are in a vulnerable situation because they are usually women who are also aging or are already elderly, who do not receive the necessary support to meet their needs. Because of the demands of providing care for Alzheimer's patients, caregivers fail to consider their own issues and develop more mechanized ways of relating to their situation, using crystallization as a defense mechanism. Stress and isolation can adversely affect the physical and mental health of caregivers.
\end{abstract}

\section{Keywords}

Elderly, Family Caregivers, Alzheimer's Disease, Care

\footnotetext{
"Corresponding author.
}

How to cite this paper: Ribeiro, B.S.S., Rezende, L.K., Sa, S.P.C. and Machado, W.C.A. (2016) The Impact of Alzheimer's Disease on the Life of Family Caregivers: A Phenomenological View. Open Journal of Nursing, 6, 333-341. 


\section{Introduction}

According to [1], the development of chronic diseases in caregivers with the subsequent need for medications is the result of work overload in the care of elders with Alzheimer's disease. The health complications which arise will be influenced by time, stage of disease, and support that the family caregiver receives.

Some studies demonstrate that there are difficulties on the part of family caregivers to delegate care to another person or institution based on the social belief that family care is ideal, that institutionalizing means abandonment when the elderly requires specialcare, and that institutionalization can lead to the death of the elderly [2].

Humans are relational beings, and their existence is linked to the expression of their experiences in the world, embracing the totality of this experience that is presented in the expression, me-the other-the world. The individual can change and act on the environment he lives in according to his experiences. Assuming the principle of adaptation and self-regulation, the person is seen in his entirety through revealed potentials as he experience a given reality [3]. Thus, the family caregiver is modified when facing the reality that Alzheimer's disease brings, and can develop or fail to develop conditions that directly influence both the way she provides care and the quality of the care provided.

Considering the changes in the life of caregivers due to the presence of an elder with a chronic disease such as Alzheimer's, and the lack of support with which to deal with the reality of Alzheimer's, the issues that guided the study were: how family caregivers of elders with Alzheimer's disease attending the Elderly and Caregiver Health Care Center perceive the activity of care?

\section{Objectives}

To describe the perception of family caregivers about the process of caring for elders with Alzheimer's disease, analyze the impact of the care process on the life of the caregiver considering biological and emotional aspects, and discuss the changes in the life of family caregivers in the light of Gestalt Therapy.

\section{Method}

This was a qualitative and descriptive study with a phenomenological analysis.

\subsection{Site}

The study was conducted at the Elderly and Caregiver Health Care Center/CASIC at the Fluminense Federal University located in the city of Niteroi, a facility which assists elderlies and caregivers in the city and surroundings. The study subjects were people who care for elders with Alzheimer's disease, are family members, and attended the Nursing Extension Project activities in the Elderly and Caregiver Health Care Center (EASIC) conducted in the CASIC/UFF.

\subsection{Inclusion/Exclusion Criteria}

The inclusion criterion was that the family caregiver must live in the same household or near the elderly with Alzheimer's disease. The exclusion criteria included secondary caregivers that help family caregivers and live in the same domicile and those who have support from other resources such as daily or weekly care in nursing homes.

\subsection{Risks}

The study did not expose the participants to any physical or psychological risk.

\subsection{Study Contributions}

The study is expected to contribute to the implementation of the Psychology Service with the focus on dementia to provide extended support to caregivers of demented elderly. The assessment of needs of caregivers and referrals to provide solutions is another benefit from the study.

\subsection{Data Collection}

Family caregivers were identified through the analysis of medical records provided by the Nursing team at 
CASIC-UFF. Those who fit the inclusion criteria were contacted via telephone. Caregivers referred to the Psychology Service were also invited to participate in the study. Initially, 30 caregivers would participate in the study (100\% of the sample) this number was established based on the assumption that it would facilitate the understanding of the phenomenon through the way caregivers experience and perceive the act of caring. However, the interviews revealed context saturation, even though this was a unique and singular experience, therefore, the sample size was established as 10 participants (33.3\% of the sample) without compromising the study.

The interviews were conducted according to the participants' availability. They were conducted individually and in the appropriate setting; participants were allowed to stop the interview at any time. The interview had an average duration of one hour and was conducted from July to September of 2014. The interviews were recorded with the participant's permission, and ethical aspects were respected. The following guiding questions initiated the interviews: How has your life been since the diagnosis of Alzheimer's disease in your family? How do you feel about it? How are you affected by this in your daily life? How can psychology contribute to the health care of the caregiver?

The participants were identified in the numerical order of interviews preceded by the letter E (i.e., E1 means interviewed 1 and so on).

\subsection{Data Analysis}

The data analysis was based on the phenomenological reduction method proposed by Edmund Husserl that means going back to the same thing, and through the adaptation of [4].

The words and sentences that most frequently appeared in the experience of caregivers were surveyed in each interview transcript and grouped into thematic units according to repetitions.

Thus, speeches of each subject were grouped in seven universal structural categories proposed by [4] temporality: descriptions of time experiences; spatialization; presentation of space experience; aspects related to the body, how they feel the impact of the experience in their bodies, what kind of relationship they establish with the body; motivation: how they understand the phenomenon seeking justifications for living the given situation, what makes them stay in the relationship; materiality: search for figures of speech, metaphors that are used and capture the totality; relationship with the world of self: identification of feelings that arose, even if not expressed in words but by bodily manifestation; relationship with others and the surroundings: trying to identify how to maintain links with the outside world besides the elderly [5].

This analysis stage was individual. During the second reading of each interview, we sought to identify the speeches that repeated and drew attention, which were highlighted. In a third reading, we tried to identify the speeches that served the universal structures being grouped in a chart (Chart 1) to visualize the situation and facilitate the phenomenological reduction for the discussion of the phenomenon.

Thus, the Intentional Analysis and Understanding of the Interview phase occurred as presented above, seeking to identify the meaning of the act of caring given by the respondent and the impact on his life; this, helped to discuss the human condition mainly in the caring situation.

Furthermore, the Contact Cycle was used, which is a Gestalt therapy construct consisting of the expression of a system of a total vital field that the body presents interactions that the self organizes through self-regulation. When the body is not updated, disturbances or cycle blocks occur, which mean disturbances in the I-world [6] The contact blocks verified in the survey were: introjection, projection, retroflexion, deflection; confluence [7].

Through the cycle we sought to understand how caregivers avoid contact and what types of psychological diseases they present throughout the process, or may arise if they are not living consciously and mindfully about themselves.

After this individual analysis stage, we set up a general chart consisting of the universal structures and speeches identified for each participant forming the whole of the interview. Therefore, after this grouping of individual themes units we sought to identify the units themes that emerged through the repetition of words.

\subsection{Ethical Aspects}

Studies with humans require attention to the legal aspects, therefore, an informed consent form was prepared according to Resolution No. 466, of December 12, 2012, from the National Health Council/MS, which, through its legal powers, establishes the guidelines and standards that regulate research involving humans.

The study was submitted to the Research Ethics Committee from the Antônio Pedro University Hospital 
(HUAP) that is linked to the Academic Master's Program in Health Care Sciences-UFF (MACCS-UFF) and approved under CAEE: 31286814.9.0000.5243 and number 686791 on 06/06/2014.

The study was developed with the researcher's resources and brought the benefit of encouraging the creation of spaces for listening and embracing caregivers of elders with Alzheimer's disease.

\section{Results and Analysis}

The study subjects were women ranging in age from 42 to 68 years who were married (7), single (2), and in a stable union (1). The time since the diagnosis of Alzheimer's disease ranged from 1 to 13 years. Only four participants had professional/technical training as a secretary, executive secretary, physiotherapist technician, and accountant; only one was still employed in the profession. Three participants were retired, and six had no source of income. Two were house owners and lived near the elderly, and eight lived with the elderly. The educational level was distributed as middle school (4), high school with technical training (4), and college (2).

The following conditions were identified in the medical records of participants: Hypertension (7), Diabetes II (3), Mitral Valve Prolapse (1), Chronic Renal Failure (1), Fibromyalgia (1), and Depression (1); one caregiver showed no medical diagnosis. Caregivers who assume the responsibility for the elderly have a degree of intimacy with the intense relationship. These participants were middle-aged women who assume the role of caregivers in addition to other roles such as homemakers, mothers, wives, grandmothers, daughters, sisters, daughters-inlaw, and sisters-in-law.

The study results confirm that the caregiver activity is still attached to the female gender; the majority of participants left their work activities to stay at home caring for the elderly. Only one maintained a job because she is the head of the household; she had the support of another caregiver during the day. According to studies on caregiver profiles, most are women occupying the position of daughters or wives and are dedicated exclusively to patient family care. This maybe linked to the social and cultural roles of women in society and the sexual division of labor. Their responsibility for caring for children make them more prepared to assume the caregiver role while men remain the financial provider for the family [8]. The perception that life does not go forward, or that the past was better than the present appeared as reality for these participants. Life and time crystallization is observed in the participants' speeches. According to Gestalt, the process of figure-background formation is a continuous coming and going with attention on things that are necessary for the individual at that time. This process is impaired for caregivers because they demonstrate that the time caring for the elderly with dementia leads to the crystallization of their desires and dreams.

Thus, the speeches from participants showed a need to return to previous experiences that brought satisfaction and included the description that life stopped in time because they do not reap results from the actions they are performing. The speeches below demonstrate this:

"I look back, and nothing has changed." E1

"I stopped my life." E5

The organismic self-regulation mentioned in Gestalt is compromised because it only occurs when the body can understand what is happening in the present, integrating thoughts and feelings that will be directed for action. Therefore, these facts demonstrate the crystallization of feelings, the family caregiver perceptions in relation to the elderly. These can paralyze the caregiver in her biopsychosocial needs. Thus, the temporal fixation related to previous experiences may result from the numerous demanded activities promoting distancing from the present moment and self.

"It was so good, I never thought I wouldgo through this, we went out a lot." E2

It is understood that the fixation with time observed in the caregivers' speeches result from dealing with a disease in which the elderly lose short-term memory, which implies a daily conduct of repetition for the caregiver and the need of avoiding accidents with the elderly. Additionally, this situation generates difficulties in understanding what is happening, which may also momentarily paralyze them.

Crystallization can compromise the quality of relationships established in the world. There is no time for social activities or activities that generate pleasure; this has a direct impact on the caregiver's quality of life.

Thus, the crystallization brought about by the illness of their elders is seen as threatening because the familiar border is exposed. The caregiver does not recognize that experience as familiar, but as an environmental burden on self. The following speech illustrates this assertion:

"I am watching him 24 hours, afraid that he will get hurt; I am available to him all the time." E9 
Therefore, the crystallization can be understood as an avoidance effect on self-needs, and a block that has a direct impact on the caregiver's awareness of her own feelings and thoughts.

It was observed that for some caregivers, the relationship with space is a way to preserve or redeem the world of self. Spatialization is understood as how a person experiences the space in the universal structure. The space discussed here refers to the housing situation that caregivers maintain or the house where he lives with the elderly.

In this study, the need to maintain the space delimited by the caregiver, that is, they sought to live near the elderly, was identified as facilitating dislocation or remaining in the elderly's home in case of worsening disease and complete dependence. It was observed through the interviews that those who care for the elderly 24 hours a day do not seek to satisfy their minimal needs such as tasting foods that they appreciate. The food and flavors are meant for the elderly, and the caregiver's basic functions are ignored. This phenomenon has repercussions in the psyche because caregivers fail to realize what is nurturing to them in the relationship with the world.

Family caregivers sought strategies that would minimize their suffering in an attempt to keep their protected territory. Avoiding moving in with the elderly and choosing the dislocation path to meet the needs of the elderly can be understood as a form of self-preservation in order to maintain mental balance and promote self-organismic regulation. The following speeches confirm this statement:

"I still keep my house; I will move in there as the last resort." E1

"I lived there too. I left, I have my partner, my life, I lived too much with my mother." E7

Therefore, getting very close to the elderly and providing the intense care demanded by Alzheimer's patients can promote suffering and generate defense mechanisms through a creative adjustment in order to cause the caregiver to remain in self-organismic regulation.

It was observed that caregivers restore balance when they to go home to organize their activities, check bill payments, and relate to other family members and activities. The need for balance in family relations was evident because some caregivers report difficulties in the relationship with spouses due to the attention given to the elderly. One participant mentions a case of betrayal, another of separation, and another of an argument that required psychotherapeutic intervention as presented below:

"I noticed a strange behavior in him; I think he got someone else." E6

"This is the case of the husband, he does not liketo take care, so I had problems yes, I also focus more on her, thinking that he is already an adult, canreason and knows his way around but people getjealous, it is not because they grew up that they will not be jealous." E8

Additional important information with respect to space is the need to ensure that the elderly will remain in the environment that is familiar in order to minimize confusion as the disease progresses. However, this can only occur if the caregiver lives in the elderly's environment and this need compromises his organismic balance.

Elderly caregivers can have their exposure border disrupted. According to [9] the exposure border is having the ability to speak your mind, expose difficulties and fears, be critical and not follow the points of a hegemonic view, check and defend personal views, be authentic, and sharefeelings. Maintaining an exposure border is important because often the caregiver lives with abuse and disrespect, a situation whichparalyzes the abilityto speak.Self-protection from exposure is a natural mechanism in humans; this is a contact boundary that allows the individual to avoid being identified or judged by others because he or she may not bear meeting the requirements and expectations generated by others (The speeches below demonstrate the magnitude of the exposure border:

"At the beginning of the treatment, I had to leave the set." E8

"I realize that she takes things experienced here at home with mom to her boyfriend's family." E3

Both exposure border and familiarity border seek to define the human experience in situations that may cause imbalance and suffering. However, when they become rigid, they promote conditions of psychic stagnation and reproduction of behaviors that are harmful to the individual. Thus, it is necessary to restore contact and search for other consciousness expanding pathways for the adaptive processes to occur.

Activities aimed at promoting the welfare of others and disregarding self-well-being are observed when family caregivers are caring for the elderly. The numerous demands compromise the caregiver's attention to self. The increased elderly dependency on the caregiver leads to increased overload and compromised health. The speeches below demonstrate this statement.

"In the eighth year, I confess that I was already very tired, worn out." E8

"My column is suffering a lot." E9 
Health occurs as the body can recognize and meet needs. It is through contact that the body self-regulates according to the principles of Gestalt. No one body is self-sufficient; it requires the world to satisfy needs. There is always interdependence between organism and environment. According to [10] the body is a part of the world.

Tiredness mentioned by the caretaker showed that because of the numerous responsibilities, she could not stop to get the relaxation and rest she needed; she showed changes in behavior and demonstrated aggression towards all members of her family. E9

"In the lack of control I suffer from anemia because I do not eat well, and if I am agitated, I lose my appetite."

“When I fight with her, my husband fights with me.” E10

The body has difficulties focusing and prioritizing what should be done when it encounters unfinished situations. The lack of comprehension is experienced by the body, which may lead to blocking the contact cycle that could be translated into mental and physical illness.

Some of the justifications presented for this phenomenon were: lack of financial resources to hire supporting services, lack of family support, and activity overload.

"I have a hard time finding a person to stay at home for a little bit so I can leave for a while because everyone is committed, have their responsibilities, their schedules." E9

"And we are left for later, some days I stress a lot, I cling to God, I ask Our Lady for strength because you feel abandoned. Everyone has their commitments."E5

These actions affect the family caregiver who is increasingly limited to carrying out the practice of care due to his emotional and psychological conditioning. Therefore, they present somatization, i.e., the discharge of psychic energy in the body.

The relationship with the world of self is a universal framework that allows the identification of feelings, which are non-expressed thoughts. However, the caregiver is intensely committed to her restricted world. The speechesbelow illustrate the thought:

"I do not say anything; I keep everything to myself." E1

“Today I do not feel anything.” E3

Physical or mental illness may result from the process of being unaware of individual needs or perceiving and dismissing them. These attitudes are not conscious: they are linked to the automatism generated by the demands of daily life, blocking contact. The needs are linked to the environment and geographical, social, and economic, and affective fields where the person lives.

The tension or psychic energy that arises in a particular region (body system) is understood as a single necessity or multiple necessities and tends to produce an effect illustrating emotions, desires, hunger, thirst, sex, sleep, and rest. Equilibrium is restored when needs are met [11]. This theme is the one that underscores the loss of the sense of existence: the body begins to function automatically without consciousness, and therefore, health is compromised because one of the elements considered critical to health, satisfaction of needs, is ignored.

The absence of contact is visible. It is through contact that man is organized. The living space is a product and result of a complex network of contacts that were made at various moments in life in the relationship with self and with others. The living space is not static, it exists, renewing itself every time a new contact occurs, it is a relational process, the expression of consciousness in the world [6].

This unit, Gratitude, reveals what motivates each participant to undertake the care of the elderly with Alzheimer's disease. The person in balance seeks to integrate the two movements that at first glance appear to be antagonistic but are, in fact, complementary. The picture that emerged of duty and gratitude demonstrates affection from the caregiver to the elderly as it is presented below:

"While caring for her, I lost that hurt. I was seven years indoors with her." E4

"I was handpicked. I pray to God to have enough strength to follow through." E9

The experience of caregiver E4 was striking because it portrays the story of a daughter who had unfinished Gestalten (perceptual configurations) with her mother, she had left home very young and returned to see her mother when her father became ill and had to be taken care of. This situation caused the rapprochement with the mother, and after her father's death, the mother developed Alzheimer's disease and was under her care. Caregiver E4 points out that such an event has provided the opportunity to forgive and modify her feelings towards her own mother.

It is shown from the speech of caregiver E10 that she has an appreciation for the elderly person she cares for because this person took care of the family all her life and now needs care.

"She fought hard to raise my brothers and me." E10 
Based on the speeches, it is noted that the caring attitude is based on two polarities, obligation/duty, and gratitude. For caregivers, there is a need to return the care that had been given in the past by the elderly.

During the study, it was observed that staying as the responsible caregiver is linked with the affective polarity in which the bonds built by experiences were highlighted and the intimate relationship that was built with the elderly predominates. This generates the physical and psychological situations that were describedin the study. The speeches below reinforce this statement:

"It is more than 58 years together, always good between us, we went out a lot, and we would drop everything." E2

"She isnot my sister-in-law she is a sister to me." E7

The deficit in using effective coping strategies such as alternative perceptions of the situation and handling/solving problems were associated with high levels of anxiety, depression, stress, and work overload [12]. Thus, psychological support for the family caregiver who lives in a state of tension and preoccupation is necessary to achieve a positive relation between the caregiver and the world.

The therapeutic setting offered bysome programs or units to caregivers of elderlieswith dementia include: (1) time providing assistance with taking care of the dementia patient, and (2) identifying how the changes are affecting the caregiver's perception of the world and finding away for her to live with the disease by becoming the agent of change. The references below present these perceptions of caregivers.

"the worst thing for me is to be hindered." E4

"I am rebuilding myself." E6

The need for discussions about best caregiver support policies to provide not only full assistance to the elderly with dementia but also to provide care for the caregiver is a concern that should be seen as a priority due to the increasing number of elders.

The family caregiver in this study sees the world and people as indifferent to their suffering experience. Therefore, staying isolated was a behavior that resulted in response to indifference: caregivers believe that they cannot count on anyone in the caring process.

"You feel in the look of others that you are being judged." E1

"I cannot talk to others because they do not like to hear." E4

The world is a set of meaningful relationships through which people are individualized and separated by their differences [3], and this process of differentiation is being determined by the contacts made. The person exists in an individual/environment field. The field differs by its borders. A boundary is a separation and connection process, and this determines the contact that leads to growth. Thus, isolation generates impoverishment in the individuation process. The movement of contact-drift away-assimilate is the basis for the healthy and dynamic process [13].

The feeling of loneliness that emerged in the study can influence the perception of the world as a hostile place where people do not care and, therefore, generates the conclusion that caregivers need to protect themselves. "The feelings flow seeking to placate the loss that the caregiver experiences. There are three main types of loss: loss of someone who loves you, or the loss of love or sense of being loved; loss of control; and loss of selfesteem” [14].

Alzheimer's disease is a gradual tracking of losses. It is not possible to teach how to cope with it. The image of the coffin going down into the pit in a burial configures the dementia process: they are the last moments of life with the person who is loved, who will be slipping away in front of the caregiver, losing uniqueness, being less present each day. The family caregiver has to adapt to this experience and live it every day.

"now he does not run away, up until one year ago, he would burst the locks." E9

"I am dealing with it; she has changed a lot." E10

This confirms the need for psychotherapeutic support to help the caregiver coping with the illness by learning to remain balanced, self-conscious, able to distinguish what is dangerous or deeply painful, and able to selfprotect from falling into severe psychological distressing processes.

"I confess that I needed therapy to lift me up from this phase." E8

Therefore, the family caregiver directly involved in the care for an elderly with Alzheimer's disease may fail to make contact with her own feelings, especially with the sadness that occurs through little or no interaction with others. Group activities, conversational spaces, and workshops may provide opportunities to be with others, decreasing isolation that they feel in their relationship with the world. 


\section{Final Considerations}

The change in the life of the person who takes care of the elderly with dementia is remarkable. The disease is complex and demands changes, not only in the life of the elderly but in the entire field that surrounds him. This requires the family caregiver to develop a broader view of the situation to avoid compromising his own life. We found that even with technical information about the disease, the family caregiver is emotionally vulnerable, carrying intense psychological distress because of the feeling that the care provided is never enough.

It is noteworthy how family relationships are affected by a significant transformation in the relational patterns of loss of communication and dialogue that leads to aggression and becomes expressed emotion providing material for behavioral changes among members. There is a loss of creative capacity that blunts emotions: some members begin to isolate themselves or seek distance to avoid contact with the heartbreakingpain of seeing the demented elderly. The production of a defensive shell that prevents the expression of affection is observed and all activities are conducted on an automation mode.

The study presented immediate contributions to the extent that the interviewees were directed to psychological care and followed up with scheduled therapeutic monitoring. Thisincreasedthe number of assisting consultations and also provided an extra day of assistance to caregivers and required an extra psychologist in the service. It is noteworthy that theservices are provided by voluntary professionals. This is an issue that needs to be reconsidered. There is a real need for a supporting network for health promotion, which includes local service and improved conditions of home visits to bedridden elders.

The development of a booklet that can help the caregiver to identify aspects related to the Alzheimer's disease is possible based on the results of this study; from possible behavioral changes to the bio-psychological alterations that can guide the caregivers. In addition, this booklet could facilitate the understanding of the disease and aid the dialogue with the health professionals who do not know the elderly's involvement, and sometimes are late in recognizing signs of depression and the early presentation of Alzheimer's disease.

The booklet may be composed of information that allow identifying behavioral changes that can be expected in the progression stages of Alzheimer's disease, alterations arising from depression in the elderly, the importance of home dialogue, guidance on the support the family caregiver needs to stay healthy, and information on the main organs that promote actions for the caregiver and family.

The difficulty in identifying people available to participate was onelimitation; some caregivers had no one to leave the elderly with.

\section{Conclusion}

We conclude that mental and physical illness may occur in caregivers who perceive that they do not have time to take care of themselves because of the many responsibilities they have assumed in taking care of elders with Alzheimer's.

\section{References}

[1] Seima, M.D. and Lenardt, M.H. (2011) The Burden of Family Caregivers of Elderly with Alzheimer's. Texts \& Contexts (Porto Alegre), 10, 388-398. http://www.redalyc.org/articulo.oa?id=321527169015

[2] Mazza, M.M.P.R. and Lefèvere, F. (2004) A Instituição asilar segundo o cuidador familiar do idoso. Saúde $e$ Sociedade, 13, 68-77.

[3] Ribeiro, J.P. (2011) O conceito de mundo e de pessoa em Gestalt-terapia: revisitando o caminho. Summus Editorial, São Paulo.

[4] Moustakas, C. (1994) Phenomenological Research Methods. Sage, Califórnia.

[5] Fukumitsu, K.O. (2013) O processo de luto do filho da pessoa que cometeu suicídio. Tese ( Doutorado em Psicologia Escolar e do Desenvolvimento Humano)—-Instituto de Psicologia, Universidade de São Paulo, São Paulo. http://www.teses.usp.br/teses/disponíveis/47/47131/tde-04072013-143625/

[6] (2007) O Ciclo do Contato: Temas básicos na abordagem gestáltica. 4th Edition, Summus, São Paulo.

[7] Polster, E. and Polster, M. (2001) Gestalt-Terapia Integrada. Summus, São Paulo.

[8] Borghi, A.C., Castro, V.C., Marcon, S.S. and Carreira, L. (2013) Sobrecarga de familiares cuidadores de idosos com Doença de Alzheimer: Um estudo comparativo. Revista Latino-Americana de Enfermagem, 21, No. 4.

[9] Silveira, T.M. and Peixoto, P.T.C. (2012) A Estética do Contato. Arquimedes Edições, Rio de Janeiro. 
[10] Perls, F.S. (2002) Ego, Fome e Agressão: uma revisão da teoria e do método de Freud. Summus Editorial, São Paulo.

[11] (1985) Gestalt-Terapia: Refazendo um caminho. 2nd Edition, Summus, São Paulo.

[12] Guedes, A.C. and Pereira, M.G. (2013) Sobrecarga, enfrentamento, Sintomas Físicos e Morbidade Psicológica em Cuidadores Familiares Dependentes Funcionais. Revista Latino-Americana de Enfermagem, 21, 935-940.

[13] Yontef, G.M. (1998) Processo, Diálogo e Awareness: Ensaios em Gestalt-Terapia. 3rd Edition, Summus, São Paulo.

[14] Viscott, D. (1982) A Linguagem dos Sentimentos. Summus, São Paulo. 